\title{
Composite Outcomes of Mortality and Readmission in Patients with Heart Failure: Retrospective Review of Administrative Datasets
}

This article was published in the following Dove Press journal: Journal of Multidisciplinary Healthcare

\author{
Afsaneh Roshanghalb (D) \\ Cristina Mazzali iD ${ }^{2}$ \\ Emanuele Lettieri (iD) \\ 'Department of Management, Economics \\ \& Industrial Engineering, Politecnico di \\ Milano, Milan, Italy; ${ }^{2}$ Quality and Clinical \\ Risk Unit, Niguarda Hospital, Milan, Italy
}

Correspondence: Afsaneh Roshanghalb Email afsaneh.roshanghalb@polimi.it

\begin{abstract}
Background: Controlling the quality of care through readmissions and mortality for patients with heart failure (HF) is a national priority for healthcare regulators in developed countries. In this longitudinal cohort study, using administrative data such as hospital discharge forms (HDFs), emergency departments (EDs) accesses, and vital statistics, we test new covariates for predicting mortality and readmissions of patients hospitalized for HF and discuss the use of combined outcome as an alternative.
\end{abstract}

Methods: Logistic models, with a stepwise selection method, were estimated on $70 \%$ of the sample and validated on the remaining $30 \%$ to evaluate 30 -day mortality, 30-day readmissions, and the combined outcome. We followed an extraction method for any-cause mortality and unplanned readmission within 30 days after incident HF hospitalization. Data on patient admission and previous history were extracted by HDFs and ED dataset.

Results: Our principal findings demonstrate that the model's discriminant ability is consistent with literature both for mortality $(\mathrm{AUC}=0.738$, CI $(0.729-0.748))$ and readmissions (AUC $=0.578$, CI $(0.562-0.594)$ ). Additionally, the discriminant ability of the composite outcome model is satisfactory (AUC $=0.675$, CI (0.666-0.684)).

Conclusion: Hospitalization characteristics and patient history introduced in the logistic models do not improve their discriminant ability. The composite outcome prediction is led more by mortality than readmission, without improvements for the comprehension of the readmission phenomenon.

Keywords: administrative health data, heart failure, mortality, patient readmission

\section{Introduction}

Heart failure (HF) is a common cardiovascular condition in the aging population of most developed countries. ${ }^{1-4}$ These patients are a priority for both healthcare regulators and professionals. Despite the significant technological advancements experienced in recent years, HF patients show a high risk of 30-day mortality when admitted to hospital $^{2,5}$ as well as a high probability of incurring multiple, 30-day unplanned readmission. ${ }^{6-8}$ In the United States of America (USA), the Hospital Readmissions Reduction Program (HRRP), established in 2012 by the Centre for Medicare and Medicaid Services (CMS), creates financial penalties for hospitals with higher-than-expected 30-day, risk-adjusted readmission rates for adults aged 65 and over. ${ }^{9,10}$ These penalties crystallize the relevance and urgency to improve such situation through the implementation of effective, evidence-based improvement strategies. ${ }^{11,12}$ In this regard, as suggested in the literature, administrative data 
linked with vital statistics offer a complimentary and reliable population-based data to investigate 30-day mortality and 30-day unplanned readmission. ${ }^{13-15}$

A literature review carried out by Ross et al $(2008)^{16}$ concluded that the use of administrative health data for predicting patient readmissions is a promising avenue for evidence-based policy-making. Patient demographic and clinical characteristics significantly associated with readmissions vary among prior studies. This review showed that when comparing previous studies, none of the patient characteristics are a consistent predictor of 30-day readmissions. Further, the discriminant ability of statistical models to predict 30-day mortality after hospitalization for HF has been found higher than that of readmissions, even if they assumed similar predicting variables. Another part of the relevant literature addresses the importance of assessing the impact of social determinants of health (SDH) of patients in the outcome of care evaluation for $\mathrm{HF}$, such as marital and income status, place of living, distance, and isolation. Considering $\mathrm{SDH}$ is promising in the way it may provide healthcare providers with local/ regional indicators of persons at risk and targeting those individuals to prevent readmission. Apart from the value of these covariates, the statistical models have been set for measuring each outcome of care (mortality or readmission) separately. ${ }^{17}$ These findings could lead to the conclusion that studies should investigate 30-day mortality and 30-day unplanned readmission separately because they have different causes and require improvement strategies. Even if this focus had the undoubted value of allowing the researchers to go more in-depth and thus improving the predictive ability of their models, ${ }^{18}$ in this manuscript we argue that there is also the need for academics, healthcare regulators, and professionals to consider that mortality and readmissions are competing outcomes. $^{19-22}$ One reason is patients who die outside the hospital will not generate readmissions, and from a theoretical perspective, it is thus critical to understanding the specific contribution of each of the two outcomes to the combined one.

This study is one of the main goals of a three-year strategic research project promoted by the Health Directorate of the Lombardy region (Northern Italy) concerning the comprehension and improvement of the care provided to patients with HF.

Within this research project, we studied the effect of patient characteristics, previous history, and in-hospital treatment in predicting the risk of mortality, readmission, and the combined outcome. Regional administrative health datasets have informed this study of HDFs, ED services, and vital statistics, all linked at the patient-level. Data were treated as confidential, and citizens' privacy was guaranteed according to the regional guidelines for the use of these data. This manuscript has a twofold contribution to the existing literature on predicting 30-day mortality and 30-day unplanned readmissions for patients with HF. First, our study improves upon previous models by evaluating the significance of variables related to the patient's previous history and treatment during hospitalization. Second, we compare and discuss the logistic model focused on the combined outcome of mortality and readmission. By doing so, we also aim at contributing to healthcare regulators and professionals, who are struggling to improve care for patients with HF while saving costs for the long-term sustainability of care delivery. ${ }^{9}$

\section{Methods}

\section{Context}

The Lombardy region in Northern Italy offers tax-based care (with limited out-of-pocket contributions) to 9.5 million inhabitants. ${ }^{23}$ Almost all hospitals in the region deliver care on behalf of the regional healthcare system and pass through a formal accreditation procedure. Because of that, hospitals have to submit required annual information to the regional administration to receive reimbursement for the care services that have been delivered. ${ }^{24}$ This systematic flow of data is collected in the regional administrative health database and currently stores reliable and consistent information on the whole population of the Lombardy region for the past 15 years. Recently, the Lombardy region has opened these data for approved studies to inform evidence-based improvement strategies for healthcare researchers and practitioners. The choice of patients with HF as piloting exercise grounds in the relevance of this cardiovascular condition for assessing the incidence of new cases (3.13 per 1000 adult inhabitants/ year in 2012), annual HF hospitalizations (53,830 in 2012), in-hospital mortality (9.4\% in 2012), and expenditure for the regional healthcare system (about 2.6 billion in 2002-2011, with a mean of 235 M€ per year).

\section{Data}

The primary source for this study is administrative health datasets including hospital discharge forms, and ED accesses of patients admitted for HF for conducting 
a retrospective chart review from 2010 to 2012. The Lombardy region as the data owner linked these data at the patient-level with the vital statistics, to make it available for the research. Lombardy region itself performed the collection and quality check of the data. Data are not publicly available and need the explicit authorization of the Lombardy region Welfare General Directorate that approved this study within a broader investigation on the usage of administrative data to support decision-making. Since our study is retrospective on anonymous, routinely collected data and without interference with the care pathways, there was no need for additional approvals from the ethical committee and the patients, given the approval from the Welfare General Directorate.

This information was essential to evaluate mortality outside the hospital. Hospital discharge forms contained information about patient characteristics (eg, sex and age) and hospital admissions (eg, date of admission, date of discharge, principal diagnosis, and comorbidities (secondary diagnoses, procedures, admission ward, etc.)). Diagnoses and procedures within the hospital discharge forms are coded using the International Classification of Diseases, 9th Revision, Clinical Modification (ICD-9-CM).

Hospitalizations for HF identified using the ICD-9-CM codes as recommended by the Agency for Healthcare Research and Quality (AHRQ) in their quality indicator of intra-hospital mortality due to HF (AHRQ 2015) and by the CMS in their risk adjustment model for capitation payments and in particular the category HCC80 (CMSHCC80, version 12). ${ }^{25}$ The ICD-9-CM codes were searched in every diagnosis position of the hospital discharge forms.

To study mortality and readmissions, we considered incident hospitalizations for HF; specifically, the first hospitalization for HF of any Lombardy region resident in the temporal window 2010 to 2012 occurred in any hospital located in the region. Considering the hospitalizations for any cause, we evaluated hospital readmissions for any cause after the incident HF hospitalization, the number of hospital admissions in the 6 months before the incident HF hospitalization, and the comorbidities affecting the patient at the incident hospitalization. Concerning comorbidities, we referred to the method proposed by Gagne et al. ${ }^{26}$ Because not all comorbidities are specified in the secondary diagnoses in the discharge forms - especially when they have not been treated during the hospitalization Sharabiani, Aylin, and Bottle ${ }^{27}$ suggested searching for comorbidities also in the previous admissions (look-back period). Thus, we considered a look-back period of 1 year before the incident HF. When chronic comorbidity was detected, it was considered to affect the patient in the subsequent hospitalizations, regardless of if it was present or not in the hospital discharge form.

\section{Outcomes}

We considered three different outcomes: mortality within 30 days from the incident hospitalization, unplanned readmissions with 30 days from the incident hospitalization, and the combined outcome of mortality or readmission. Mortality was evaluated considering intra-hospital and out-of-hospital mortality for all causes using the regional vital statistics. Readmissions were defined as unplanned hospitalizations for any cause within 30 days after the incident HF admission. Hospitalization was not considered a readmission if the patient was transferred from another hospital, if it was planned and if it occurred more than 30 days after the incident hospitalization. To evaluate readmissions, we excluded patients who died during the incident admission or within 10 days from discharge. The last choice was made to exclude patients who decided to spend his/her last life days at home rather than in hospital. Finally, for the combined outcome, we considered the occurrence of at least one between 30-day mortality and 30-day unplanned readmission.

\section{Statistical Models}

The choice of explanatory variables for estimating outcomes was based on past literature contributions ${ }^{22,28}$ as well as on available data. We considered the following variables: age, sex, in-hospital length of stay, number of admissions, number of ED accesses for any cause in the 6 months before the incident HF event, the type of admission ward, the process of care, and comorbidities. The variable "admission ward" has two levels to distinguish between patients directly admitted in a cardiology ward or unit from patients admitted in other wards. This variable is assumed to be a proxy of the correct placement of the patient. The process of care was obtained by categorizing the procedures which occurred during hospitalization according to the Procedures-Classes-Tools proposed by the AHRQ. ${ }^{29}$ Procedures have been divided into minor diagnostic, minor therapeutic, major diagnostic, and major therapeutic. We considered the process of care to be a binary variable differentiating between major therapeutic procedures and other procedures or none procedure at all. Finally, we examined the following comorbidities, 
evaluated through the algorithm by Gagne et al: ${ }^{26}$ metastatic cancer, renal failure, hemiplegia, any tumor, cardiac arrhythmias, chronic pulmonary disease, coagulopathy, complicated diabetes, deficiency anemia, fluid and electrolyte disorders, peripheral vascular disorder, psychosis, pulmonary circulation disorders, and hypertension.

The effect of patient characteristics on mortality and readmission was evaluated using a multivariable logistic model. We estimated the predictive model using a random sample of about $70 \%$ of our dataset and validated on the remaining $30 \%$. Covariates of the outcome were selected through a stepwise selection method. The model included only variables with a minimum p-value of 0.20 then p-value required to remain in the model was 0.05 . We calculated the Area Under the Curve (AUC) for all the models to evaluate their discriminant ability. The threshold to maximize the Youden index (ie, sensitivity + specificity -1 ) was assessed for all the models ${ }^{28}$ as well as the associated sensitivity (SE), specificity (SP), positive and negative predictive values (PPV and NPV, respectively). Data management and statistical analysis were performed using SAS 9.4.

\section{Results}

\section{Descriptive Analysis}

The number of incident hospitalizations for HF from January 2010 to November 2012 was 73,802. We considered incident hospitalizations until November to leave at least 30 days free to account for 30-day mortality and readmissions. The number of patients who died within 30 days from discharge was 9801 (13.3\%); 6293 of them died during the hospitalization. After the exclusion of patients died during incident event or within 10 days from discharge, there were a total of 65,953 hospitalizations that could generate unplanned readmission. The total number of 30-day unplanned readmissions was 4460 (6.8\%), while the number of patients experiencing the composite outcome was 14,264 out of $73,802(19.1 \%)$. The characteristics of patients at the incident hospitalization are shown in Table 1 for the whole sample (2nd column) and the readmission sample ( $3 \mathrm{rd}$ column). The characteristics of patients who died during hospitalization or within 10 days are also provided in Table 1 (4th and 5th columns). Patients who died within 10 days were older and had a higher percentage of a tumor and metastatic cancer than patients considered for readmission. They shared similar characteristics with patients who died in the hospital except for the presence of chronic pulmonary diseases, tumors, and metastatic cancer. Therefore, the assumption that those patients were facing a terminal condition appears to be correct.

\section{Results About 30-Day Mortality}

Results of the logistic regression on 30-day mortality are presented in Table 2. Patients with metastatic cancer or any tumor present a higher risk of mortality when compared with other patients. Other comorbidities found associated with a higher risk of death are fluid and electrolyte disorders, coagulopathy, and hemiplegia. We found hypertension to be associated with a lower risk of death, confirming literature. ${ }^{26}$ As Gagne et $\mathrm{al}^{26}$ argued, hypertension should not be interpreted as a protective factor, but as a signal of other factors that are inversely correlated with mortality (eg, physicians might have explicitly coded hypertension only for those patients without other more severe comorbidities, thus signaling healthier individuals). Other comorbidities, such as arrhythmia, chronic pulmonary diseases, and pulmonary circulatory diseases, are also associated with a lower risk of death. This counterintuitive result could be because such comorbidities are likely to be related to other heart diseases and that these patients were treated with adequate cardiac therapies that act as protecting factors for the risk of death.

The number of previous admissions and ED accesses have been found to be positively associated with the risk of death. Patients admitted to cardiology wards/units and undergoing major procedures have been associated with a lower probability of 30-day mortality. The discriminant ability of the model was quite good for the training set $(\mathrm{AUC}=0.750 ;$ Confidence Interval $(\mathrm{CI})=0.745-0.756)$ and was confirmed for the validation set $(\mathrm{AUC}=0.739$; $\mathrm{CI}$ $=(0.729-0.748)$, see Figure 1). The Youden index estimated on the validation set is associated with $\mathrm{SE}=0.66$, $\mathrm{SP}=0.69, \mathrm{PPV}=0.24$, and NPV $=0.93$ (see Table 3 ).

\section{Results on 30-Day Unplanned Readmissions}

Among variables reflecting in-hospital treatment, the hospital length of stay and the presence of major procedures have been found to be positively associated with a higher risk of readmission (see Table 2). Admittance into cardiology wards/units has a protective effect for readmission (as also found for mortality). As for patient history, only the number of previous admissions is positively associated 
Table I Patient Characteristics at the Incident HF Hospitalization: Mortality and Readmission Samples; Patients Died During the Hospitalization and Within 10 Days Have Been Excluded from the Readmission Sample

\begin{tabular}{|c|c|c|c|c|}
\hline Patient Characteristics & $\begin{array}{l}\text { Sample for } \\
\text { Mortality }(73,802)\end{array}$ & $\begin{array}{l}\text { Sample for } \\
\text { Readmissions } \\
(65,953)\end{array}$ & $\begin{array}{l}\text { In-Hospital } \\
\text { Deaths (6293) }\end{array}$ & $\begin{array}{l}\text { Patients Died Within } \\
\text { I } 0 \text { Days ( } 1556 \text { ) }\end{array}$ \\
\hline Women (n, \%) & $38,271(51.9)$ & $33,950(51.5)$ & $3492(55.5)$ & $829(53.3)$ \\
\hline $\begin{array}{l}\text { Age (years) } \\
\text { Mean (std. dev.) } \\
\text { Median (IQR) }\end{array}$ & $\begin{array}{l}78.0(11.6) \\
80(72-86)\end{array}$ & $\begin{array}{l}77.3(11.7) \\
80(72.85)\end{array}$ & $\begin{array}{l}83.7(9.2) \\
85(80-89)\end{array}$ & $\begin{array}{l}84.0(9.0) \\
85(79-90)\end{array}$ \\
\hline $\begin{array}{l}\text { In-hospital length of stay (days) } \\
\text { Mean (std. dev.) } \\
\text { Median (IQR) } \\
\text { Patient admitted in a cardiology ward } \\
(\mathrm{n}, \%)\end{array}$ & $\begin{array}{l}10.8(8.1) \\
9(6-14) \\
18,345(24.9)\end{array}$ & $\begin{array}{l}10.8(7.7) \\
9(6-14) \\
17,735(26.9)\end{array}$ & $\begin{array}{l}9.6(10.4) \\
6(2-13) \\
482(7.7)\end{array}$ & $\begin{array}{l}14.3(10.9) \\
12(7-18) \\
128(8.23)\end{array}$ \\
\hline Major therapeutic procedures (n, \%) & $5721(7.8)$ & $5428(8.23)$ & $249(3.4)$ & $44(2.8)$ \\
\hline $\begin{array}{l}\text { Number of ED accesses in the previous } \\
\text { six months }(n, \%) \\
0 \\
1 \\
2+\end{array}$ & $\begin{array}{l}53,729(72.8) \\
14,554(19.7) \\
5519(7.5)\end{array}$ & $\begin{array}{l}48,223(73.1) \\
12,922(19.6) \\
4808(7.3)\end{array}$ & $\begin{array}{l}4419(70.2) \\
\mid 303(20.7) \\
57 \mid(9.7)\end{array}$ & $\begin{array}{l}1087(69.9) \\
329(21.1) \\
140(9.0)\end{array}$ \\
\hline $\begin{array}{l}\text { Number of hospitalizations in the } \\
\text { previous six months (n, \%) } \\
0 \\
1 \\
2+\end{array}$ & $\begin{array}{l}57,986(78.6) \\
11,976(16.2) \\
3840(5.2)\end{array}$ & $\begin{array}{l}52,500(79.6) \\
10,286(15.6) \\
3167(4.8)\end{array}$ & $\begin{array}{l}4447(70.7) \\
\mid 325(2|.|) \\
52 \mid(8.3)\end{array}$ & $\begin{array}{l}1039(66.8) \\
365(23.5) \\
152(9.8)\end{array}$ \\
\hline $\begin{array}{l}\text { In-hospital deaths } \\
\text { Cardiac arrhythmias (n, \%) } \\
\text { Hypertension (n, \%) } \\
\text { Chronic pulmonary disease (n, \%) } \\
\text { Renal failure (n, \%) } \\
\text { Deficiency anemias (n, \%) } \\
\text { Any tumor (n, \%) } \\
\text { Pulmonary circulation disorders (n, \%) } \\
\text { Peripheral vascular disorder (n, \%) } \\
\text { Complicated diabetes (n, \%) } \\
\text { Fluid and electrolyte disorders (n, \%) } \\
\text { Metastatic cancer (n, \%) } \\
\text { Hemiplegia (n, \%) } \\
\text { Psychosis (n, \%) } \\
\text { Coagulopathy (n, \%) }\end{array}$ & $\begin{array}{l}6293(8.5) \\
23,149(31.5) \\
13,024(17.7) \\
12,247(16.7) \\
8415(11.4) \\
3925(5.3) \\
3997(5.4) \\
3049(4.1) \\
2906(4.0) \\
2219(3.0) \\
2141(2.9) \\
1269(1.7) \\
467(0.6) \\
383(0.5) \\
308(0.4)\end{array}$ & $\begin{array}{l}\text { N.A. } \\
21,143(32.1) \\
12,150(18.5) \\
11, I 10(16.9) \\
7332(11.4) \\
3446(5.2) \\
3139(4.8) \\
2870(4.4) \\
2582(3.9) \\
2033(3.1) \\
1657(2.5) \\
860(1.3) \\
369(0.6) \\
348(0.5) \\
240(0.4)\end{array}$ & $\begin{array}{l}6293(100.0) \\
1520(24.5) \\
677(10.9) \\
857(13.8) \\
844(13.6) \\
367(5.9) \\
630(10.2) \\
131(2.1) \\
258(4.2) \\
148(2.4) \\
386(6.2) \\
288(4.7) \\
82(1.3) \\
29(0.5) \\
53(0.9)\end{array}$ & $\begin{array}{l}\text { N.A. } \\
486(3 \mid .6) \\
197(I 2.8) \\
280(18.2) \\
239(15.5) \\
112(7.3) \\
228(14.8) \\
48(3.1) \\
66(4.3) \\
38(2.5) \\
98(6.4) \\
121(7.9) \\
16(1.0) \\
6(0.4) \\
15(I .0)\end{array}$ \\
\hline
\end{tabular}

Abbreviations: Std. dev, standard deviation; IQR, inter-quartile range.

with readmissions. The comorbidities significantly associated with readmission are reported in Table 2. Unlike what found for mortality, all of them are risk factors for 30-day unplanned readmissions. The discriminant ability of the model on the training set was very poor (AUC = $0.590 ; \mathrm{CI}=(0.579-0.601))$ and was confirmed in the validation set $(\mathrm{AUC}=0.578 ; \mathrm{CI}=(0.562-0.594)$, see
Figure 1). The Youden index, evaluated in the validation set, was associated with $\mathrm{SE}=0.44, \mathrm{SP}=0.68, \mathrm{PPV}=0.09$, and NPV $=0.94$ (see Table 3 ).

\section{Results on the Combined Outcome}

All the variables associated with mortality were also associated with the combined outcome, except for major 
Table 2 Results of the Logistic Model on 30-Day Mortality, Unplanned Readmissions, and Mortality or Unplanned Readmissions Using a Stepwise Selection Method. In Grey, The Covariates Associated with the Composite Outcome

\begin{tabular}{|c|c|c|c|c|c|c|c|c|c|c|c|c|}
\hline \multirow{3}{*}{$\begin{array}{l}30 \text { Days } \\
\text { Effect } \\
\text { Sex (M vs F) }\end{array}$} & \multicolumn{4}{|c|}{ Mortality } & \multicolumn{4}{|c|}{ Readmission } & \multicolumn{4}{|c|}{ Mortality OR Readmission } \\
\hline & \multirow{2}{*}{$\begin{array}{l}\text { OR } \\
0.850\end{array}$} & \multicolumn{2}{|c|}{$95 \% \mathrm{Cl}$} & \multirow{2}{*}{$\frac{\mathbf{p}}{<0.0001}$} & \multirow[t]{2}{*}{ OR } & \multicolumn{2}{|c|}{$95 \% \mathrm{Cl}$} & $\mathbf{p}$ & \multirow{2}{*}{$\frac{\text { OR }}{0.925}$} & \multicolumn{2}{|c|}{$95 \% \mathrm{Cl}$} & \multirow{2}{*}{$\frac{\mathbf{p}}{0.0013}$} \\
\hline & & 0.804 & 0.899 & & & & & & & 0.882 & 0.970 & \\
\hline Age (years) & 1.075 & 1.072 & 1.079 & $<0.0001$ & 0.993 & 0.990 & 0.997 & $<0.0001$ & 1.039 & $\mathrm{I} .037$ & 1.042 & $<0.0001$ \\
\hline $\begin{array}{l}\text { Number of ED accesses in the } \\
\text { previous six months }\end{array}$ & 1.047 & 1.012 & 1.083 & 0.0088 & & & & & 1.032 & 1.002 & 1.062 & 0.0332 \\
\hline $\begin{array}{l}\text { Number of hospitalizations in the } \\
\text { previous six months }\end{array}$ & 1.424 & 1.367 & 1.483 & $<0.0001$ & 1.241 & 1.181 & 1.306 & $<0.0001$ & 1.335 & 1.289 & 1.383 & $<0.0001$ \\
\hline In-hospital length of stay & & & & & 1.015 & 1.010 & 1.019 & $<0.0001$ & 1.004 & 1.002 & 1.007 & 0.0020 \\
\hline $\begin{array}{l}\text { Patient admitted in cardiology } \\
\text { ward (Yes vs No) }\end{array}$ & 0.400 & 0.366 & 0.438 & $<0.0001$ & 0.769 & 0.700 & 0.845 & $<0.0001$ & 0.515 & 0.482 & 0.550 & $<0.0001$ \\
\hline $\begin{array}{l}\text { Major therapeutic procedure (Yes } \\
\text { vs No) }\end{array}$ & 0.809 & 0.703 & 0.930 & 0.0030 & 1.225 & 1.075 & 1.396 & 0.0023 & & & & \\
\hline Metastatic cancer (Yes vs No) & 3.608 & 3.070 & 4.241 & $<0.0001$ & 1.367 & 1.045 & 1.790 & 0.0227 & 2.893 & 2.484 & 3.370 & $<0.0001$ \\
\hline Renal diseases (Yes vs No) & & & & & 1.139 & 1.020 & 1.272 & 0.0207 & 1.085 & 1.013 & 1.161 & 0.0203 \\
\hline Hemiplegia (Yes vs No) & 2.348 & 1.786 & 3.085 & $<0.0001$ & 1.506 & 1.024 & 2.214 & 0.0375 & 1.851 & 1.452 & 2.360 & $<0.0001$ \\
\hline Any tumor (Yes vs No) & 1.748 & $1.57 \mid$ & 1.946 & $<0.0001$ & & & & & 1.515 & 1.377 & 1.666 & $<0.0001$ \\
\hline Arrhythmia (Yes vs No) & 0.743 & 0.700 & 0.790 & $<0.0001$ & & & & & 0.807 & 0.767 & 0.848 & $<0.0001$ \\
\hline $\begin{array}{l}\text { Chronic pulmonary disease (Yes vs } \\
\text { No) }\end{array}$ & 0.790 & 0.730 & 0.854 & $<0.000$ I & 1.168 & 1.064 & 1.283 & 0.0011 & 0.880 & 0.827 & 0.935 & $<0.0001$ \\
\hline Coagulopathy (Yes vs No) & 2.452 & 1.766 & 3.404 & $<0.0001$ & & & & & 1.567 & 1.167 & 2.103 & 0.0028 \\
\hline Anemia (Yes vs No) & 0.807 & 0.720 & 0.904 & 0.0002 & 1.166 & 1.004 & 1.353 & 0.0445 & & & & \\
\hline Psychosis (Yes vs No) & & & & & 1.597 & 1.075 & 2.373 & 0.0205 & & & & \\
\hline $\begin{array}{l}\text { Fluid and electrolyte disorders } \\
\text { (Yes vs No) }\end{array}$ & 1.753 & 1.547 & 1.988 & $<0.0001$ & & & & & 1.533 & 1.368 & 1.717 & $<0.0001$ \\
\hline $\begin{array}{l}\text { Pulmonary circulatory diseases } \\
\text { (Yes vs No) }\end{array}$ & 0.687 & 0.575 & 0.822 & $<0.0001$ & & & & & & & & \\
\hline Hypertension (Yes vs No) & 0.556 & 0.512 & 0.604 & $<0.0001$ & 1.103 & 1.006 & 1.210 & 0.0371 & 0.712 & 0.668 & 0.760 & $<0.0001$ \\
\hline
\end{tabular}

Abbreviations: $\mathrm{OR}$, odds ratio; $95 \% \mathrm{Cl}, 95 \%$ confidence interval.

therapeutic procedures, anemia, and pulmonary circulatory diseases (see Table 2). They preserved the same type of association (positive or negative) they have had with mortality even when it was in contrast with their effect on readmission (age, chronic pulmonary diseases, and hypertension) or when they had not any significant effect on readmission (sex, number of previous hospitalizations, tumor, arrhythmia, coagulopathy, and fluid and electrolyte disorders). Major therapeutic procedures and anemia have had opposite effects on mortality and readmissions, but the association was not particularly strong for both the outcomes (see Table 2). Length of stay and renal diseases were the only variables significantly predicting the combined outcome, which were associated with readmissions but not with mortality (see Table 2). The discriminant ability of the model on the training set was fair (AUC = 0.679 ; $\mathrm{CI}=(0.673-0.685))$ and it was confirmed in the validation set $(\mathrm{AUC}=0.675 ; \mathrm{CI}=(0.667-0.684)$, see
Figure 1). The Youden index, evaluated in the validation set, was associated with $\mathrm{SE}=0.63, \mathrm{SP}=0.62 ; \mathrm{PPV}=0.28$, and NPV $=0.88$ (see Table 3 ).

\section{Discussion}

The discriminant ability of the two models on 30-day mortality and 30-day unplanned readmissions was similar to those shown in past studies. ${ }^{11,22,28}$ Predicting readmissions because of demographic and clinical characteristics of the patient was the main avenue while not being a trivial exercise. In this regard, administrative health data have been suffering from the lack of detailed clinical information that could improve the prediction ability of the models. To improve the discriminant ability of our models, we introduced covariates on the patient's history and treatment during hospitalization. Among them, the number of previous hospitalizations and the admission ward/unit have been found associated with mortality, readmissions, and 

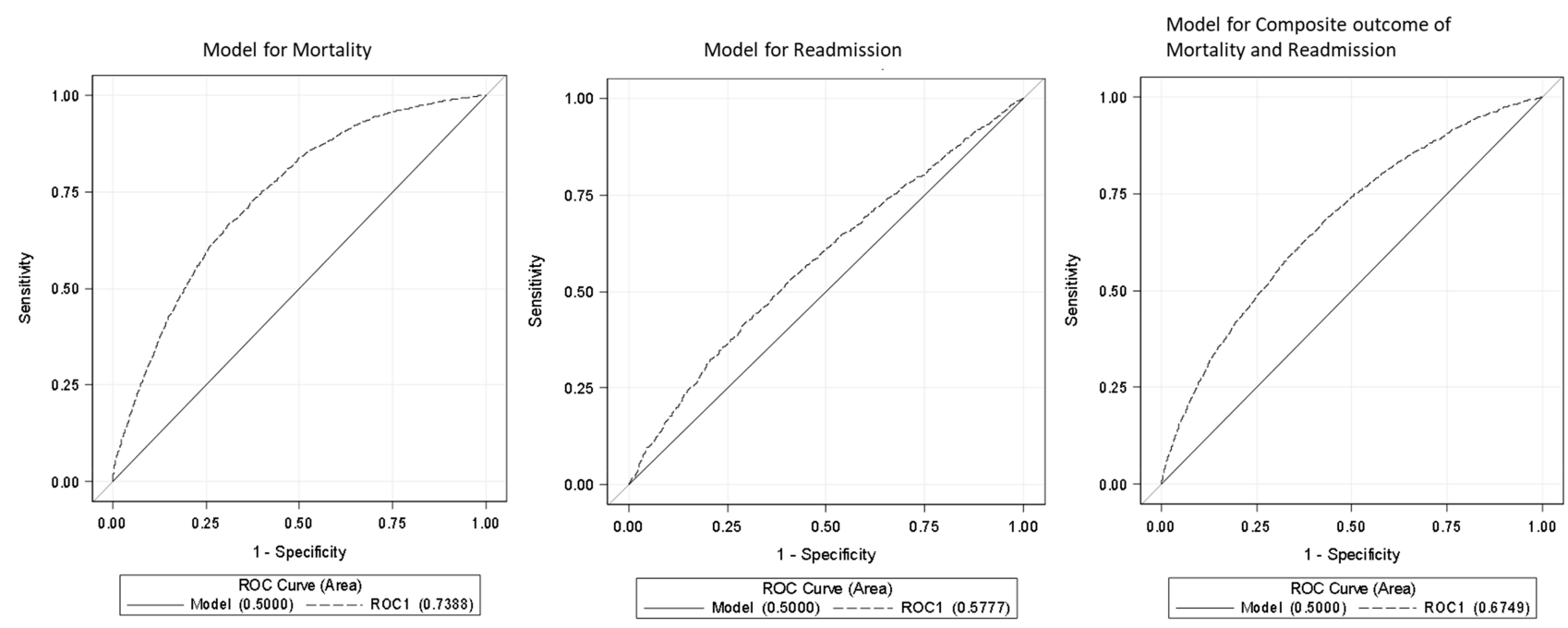

Figure I Receiver Operator Characteristic (ROC) curves for mortality, readmission, and composite outcome of mortality and readmission at 30 days. AUC indicates area under the curve (Mann-Whitney U-Statistic); $95 \%$ confidence interval for mortality ROC ( 0.7297 to 0.7480 ), readmission ROC (0.56I5 to 0.5939 ), and composite outcome of mortality and readmission (0.6660 to 0.6839$)$.

with the combination of them. Supported by earlier studies on the outcome of care measurements for HF, better outcomes could be achieved when cardiologists take the lead during the hospitalization. ${ }^{19}$ Additionally, patients whose medical/nursing teams followed professional guidelines for treatment/management have been shown to do better.

Although the Lombardy region administrative health data do not store this information, we included in our study the admission ward as a proxy of the correct placement of the patient and the physicians in charge of her hospitalization. The risk reduction associated with the admission to a cardiologic ward suggests the importance of in-hospital patient pathways, even if we cannot exclude the effect of a non-controlled bias for patients' clinical condition.

Our results show that the introduction of new covariates on patient history and in-hospital treatment and the exclusion of patients who died within 10 days from discharge does not improve the discriminant ability of the model on readmission, which remains similar to those reported in past studies. ${ }^{22,28}$ Previous studies ${ }^{28}$ developed a model to predict readmissions for all cardiac diseases with fair discriminant ability (AUC $=0.64$ ). It is worth to be noted that while they evaluated readmissions on a specific subset of hospitalizations (such as MCD-5: diseases of the circulatory system), our work implemented a broader definition of HF and considered readmissions for all causes. The model on the combined outcome has decent performance. Out of 15 variables associated with the combined outcome, 13 were also associated with mortality. Half of the variables affecting the combined outcome also affect both mortality and readmissions.

Additionally, these variables always had the same effects shown on mortality for the combined outcome as well, even if in contrast with the impact on readmission. However, their effects on the combined outcome were softened concerning that on mortality. Six of the variables

Table 3 Performance of the Model Applying the Youden Index as Threshold on the Three Outcomes in the Validation Set

\begin{tabular}{|l|l|l|l|l|l|l|}
\hline 30 Days & AUC $(\mathbf{C l})$ & Youden Index $(\mathbf{P})$ & SE $(\mathbf{C l})$ & SP $(\mathbf{C l})$ & $\mathbf{P P V}(\mathbf{C I})$ & $\mathbf{N P V}(\mathbf{C I})$ \\
\hline Mortality & $\begin{array}{l}0.7388 \\
(0.7297-0.7480)\end{array}$ & $0.35(0.15)$ & $\begin{array}{l}0.66 \\
(0.64-0.68)\end{array}$ & $\begin{array}{l}0.69 \\
(0.68-0.69)\end{array}$ & $\begin{array}{l}0.24 \\
(0.23-0.25)\end{array}$ & $\begin{array}{l}0.93 \\
(0.926-0.934)\end{array}$ \\
\hline Readmissions & $\begin{array}{l}0.5777 \\
(0.5615-0.5939)\end{array}$ & $0.12(0.07)$ & $\begin{array}{l}0.44 \\
(0.41-0.48)\end{array}$ & $\begin{array}{l}0.68 \\
(0.67-0.69)\end{array}$ & $\begin{array}{l}0.09 \\
(0.08-0.10)\end{array}$ & $\begin{array}{l}0.94 \\
(0.939-0.947)\end{array}$ \\
\hline $\begin{array}{l}\text { Mortality or } \\
\text { readmission }\end{array}$ & $\begin{array}{l}0.6749 \\
(0.6660-0.6839)\end{array}$ & $0.25(0.20)$ & $\begin{array}{l}0.63 \\
(0.62-0.65)\end{array}$ & $\begin{array}{l}0.62 \\
(0.61-0.62)\end{array}$ & $\begin{array}{l}0.28 \\
(0.27-0.29)\end{array}$ & $\begin{array}{l}0.88 \\
(0.87 I-0.882)\end{array}$ \\
\hline
\end{tabular}

Abbreviations: AUC, area under the curve; SE, sensitivity; SP, specificity; PPV, positive predictive value; NPV, negative predictive value; Cl, confidence interval. 
affecting the combined outcome were associated with mortality but not with readmissions.

\section{Conclusion}

As a result of our analyses, the composite outcome has been found to offer a weaker clinical meaning compared to each outcome separately. Additionally, its prediction seems to be more related to mortality rather than readmission, also given the limited predictive ability of the model on readmissions. As a consequence, we argue that considering the composite outcome did not improve the comprehension of the factors associated with mortality and readmissions. Recent research showed that hospitals in the Lombardy region were more in control - in terms of actual vs risk-adjusted predicted results for 30-day mortality than 30-day unplanned readmissions for patients with HF. We experienced limitations accessing other relevant and vital information, for our analyses, such as the social determinants of patients with HF. Also, examining models over a wider timespan can provide a better understanding of the past and present situation. Future research can take advantage of the linkage of administrative health data with different registries to provide a better view of monitoring the quality of care for these patients. Measuring allcause mortality, as it is evaluated in this study, may raise questions as to if was death unrelated to HF. One discussion to this line would be the patient's hospitalization itself, with HF history, would be a risk factor for mortality.

In this view, healthcare regulators and professionals urge further research to understand the "readmission phenomenon" by measuring social and organizational determinants as risk predictors aiming to deliver better care and saving costs as well as improving public health surveillance systems to provide better information about the prevalence of chronic conditions.

\section{Disclosure}

Dr Emanuele Lettieri reports grants from Italian Ministry of Health and Lombardy Region, during the conduct of the study. The authors report no other conflicts of interest in this work.

\section{References}

1. Mazzali C, Paganoni AM, Ieva F, et al. Methodological issues on the use of administrative data in healthcare research: the case of heart failure hospitalizations in Lombardy region, 2000 to 2012. Health Serv Res. 2016;16:1-10. doi:10.1186/s12913-016-1489-0

2. Ballard DJ, Ogola G, Fleming NS, et al. Impact of a standardized heart failure order set on mortality, readmission, and quality and costs of care. Int J Qual Health Care. 2010;22(6):437-444. doi:10.1093/intqhe/mzq051
3. Putnam W, Bower KN, Cox J, et al. Quality indicators for cardiac care: national standards in a community context. $J$ Health Serv Res Policy. 2006;11(1):5-12. doi:10.1258/135581906775094226

4. Keenan PS, Normand SLT, Lin Z, et al. An administrative claims measure suitable for profiling hospital performance on the basis of 30-day all-cause readmission rates among patients with heart failure. Circ Cardiovasc Qual Outcomes. 2008;1(1):29-37. doi:10.1161/ CIRCOUTCOMES.108.802686

5. Roshanghalb A, Mazzali C, Lettieri E. Multi-level models for heart failure patients' 30-day mortality and readmission rates: the relation between patient and hospital factors in administrative data. $B M C$ Health Serv Res. 2019;19(1):1012. doi:10.1186/s12913-019-4818-2

6. Bottle A, Honeyford K, Chowdhury F, Bell D, Aylin P. Factors associated with hospital emergency readmission and mortality rates in patients with heart failure or chronic obstructive pulmonary disease: a national observational study. Health Serv Deliv Res. 2018;6:26. doi:10.3310/hsdr06260

7. Kim H, Hung WW, Paik MC, et al. Predictors and outcomes of unplanned readmission to a different hospital. Int $J$ Qual Health Care. 2015;27(6):513-519. doi:10.1093/intqhe/mzv082

8. Lu N, Huang KC, Johnson JA. Reducing excess readmissions: promising effect of hospital readmissions reduction program in US hospitals. Int J Qual Health Care. 2016;28(1):53-58. doi:10.1093/ intqhe/mzv090

9. Nuckols TK. County-level variation in readmission rates: implications for the hospital readmission reduction program's potential to succeed. Health Serv Res. 2015;50(1):12-19. doi:10.1111/14756773.12268

10. Arbaje AI, Yu Q, Wang J, Leff B. Senior services in US hospitals and readmission risk in the Medicare population. Int J Qual Health Care. 2017;29(6):845-852. doi:10.1093/intqhe/mzx112

11. Gu Q, Koenig L, Faerberg J, Steinberg CR, Vaz C, Wheatley MP. The medicare hospital readmissions reduction program: potential unintended consequences for hospitals serving vulnerable populations. Health Serv Res. 2009;49(3):818-837. doi:10.1111/1475-6773.12150

12. Murtaugh CM, Deb P, Zhu C, et al. Reducing readmissions among heart failure patients discharged to home health care: effectiveness of early and intensive nursing services and early physician follow-up. Health Serv Res. 2017;52(4):1445-1472. doi:10.1111/1475-6773.12537

13. Gasperoni F, Ieva F, Barbati G, et al. Multi-state modelling of heart failure care path: a population-based investigation from Italy. PLoS One. 2017;12(6):1-15. doi:10.1371/journal.pone.0179176

14. Krumholz HM, Hsieh A, Dreyer RP, Welsh J, Desai NR, Dharmarajan K. Trajectories of risk for specific readmission diagnoses after hospitalization for heart failure, acute myocardial infarction, or pneumonia. PLoS One. 2016;11(10):1-14. doi:10.1371/journal.pone.0160492

15. Roshanghalb A, Lettieri E, Aloini D, Cannavacciuolo L, Gitto S, Visintin F. What evidence on evidence-based management in healthcare? Manag Decis. 2018;56(10):2069-2084. doi:10.1108/ MD-10-2017-1022

16. Ross JS, Mulvey GK, Stauffer B, et al. Statistical models and patient predictors of readmission for heart failure: a systematic review. Arch Intern Med. 2008;168(13):1371-1386. doi:10.1001/archinte.168.13.1371

17. Calvillo-King L, Arnold D, Eubank KJ, et al. Impact of social factors on risk of readmission or mortality in pneumonia and heart failure: systematic review. $J$ Gen Intern Med. 2013;28(2):269-282. doi:10.1007/s11606-012-2235-x

18. Shahian DM, Iezzoni LI, Meyer GS, Kirle L, Normand SLT. Hospital-wide mortality as a quality metric: conceptual and methodological challenges. Am J Med Qual. 2012;27(2):112-123. doi: $10.1177 / 1062860611412358$

19. Jong P, Gong Y, Liu PP, Austin PC, Lee DS, Tu JV. Care and outcomes of patients newly hospitalized for heart failure in the community treated by cardiologists compared with other specialists. Circulation. 2003;108(2):184-191. doi:10.1161/01.CIR.0000080290. 39027.48 
20. Huynh QL, Saito M, Blizzard CL, et al. Roles of nonclinical and clinical data in prediction of 30-day rehospitalization or death among heart failure patients. J Card Fail. 2015;21(5):374-381. doi:10.1016/ j.cardfail.2015.02.002

21. Neuman HB, Michelassi F, Turner JW, Bass BL. Surrounded by quality metrics: what do surgeons think of ACS-NSQIP? Surgery. 2009;145(1):27-33. doi:10.1016/j.surg.2008.08.002

22. Au AG, McAlister FA, Bakal JA, Ezekowitz J, Kaul P, Van Walraven C. Predicting the risk of unplanned readmission or death within 30 days of discharge after a heart failure hospitalization. Am Heart J. 2012;164(3):365-372. doi:10.1016/j. ahj.2012.06.010

23. France G, Taroni F, Donatini A. The Italian health-care system. Health Econ. 2005;14(SUPPL. 1):187-202. doi:10.1002/hec.1035

24. Cavalieri M, Gitto L, Guccio C. Reimbursement systems and quality of hospital care: an empirical analysis for Italy. Health Policy. 2013;111(3):273-289. doi:10.1016/j.healthpol.2013.05.014
25. Pope GC, Kautter J, Ingber MJ, Freeman S, Sekar R, Newhart C. Evaluation of the CMS-HCC risk adjustment model final report evaluation of the CMS-HCC risk adjustment model. 2011. (Project Num. 0209853).

26. Gagne JJ, Glynn RJ, Avorn J, Levin R, Schneeweiss S. A combined comorbidity score predicted mortality in elderly patients better than existing scores. J Clin Epidemiol. 2011;64(7):749-759. doi:10.1016/j. jclinepi.2010.10.004

27. Sharabiani MTA, Aylin P, Bottle A. Systematic review of comorbidity indices for administrative data. Med Care. 2012;50(12):1109-1118. doi:10.1097/MLR.0b013e31825f64d0

28. Wallmann R, Llorca J, Gomez-Acebo I, Ortega AC, Roldan FR, Dierssen-Sotos T. Prediction of 30-day cardiac-related-emergencyreadmissions using simple administrative hospital data. Int J Cardiol. 2013;164(2):193-200. doi:10.1016/j.ijcard.2011.06.119

29. AHRQ. Heart Failure Mortality Rate Technical Specifications IQI16. Vol. 14; 2015.
Journal of Multidisciplinary Healthcare

\section{Publish your work in this journal}

The Journal of Multidisciplinary Healthcare is an international, peerreviewed open-access journal that aims to represent and publish research in healthcare areas delivered by practitioners of different disciplines. This includes studies and reviews conducted by multidisciplinary teams as well as research which evaluates the results or conduct of such teams or healthcare processes in general. The journal

\section{Dovepress}

covers a very wide range of areas and welcomes submissions from practitioners at all levels, from all over the world. The manuscript management system is completely online and includes a very quick and fair peer-review system. Visit http://www.dovepress.com/testimonials php to read real quotes from published authors. 